\title{
Lactic acidosis due to metformin therapy in a low risk patient
}

\author{
D.J. Tymms and B.A. Leatherdale \\ Diabetic Department, Royal South Hants Hospital, Southampton SO9 1BG, UK.
}

\begin{abstract}
Summary: A 55 year old diabetic woman treated with chlorpropamide and metformin for three years presented with acute oliguric renal failure and lactic acidosis from which she died. The plasma metformin level was very high suggesting that the lactic acidosis was caused by the drug. There were no contraindications to metformin therapy and renal function was normal three months previously. This case demonstrates that lactic acidosis can occur as a result of metformin therapy in the absence of pre-existing risk factors.
\end{abstract}

\section{Introduction}

Previous reports of lactic acidosis associated with metformin therapy are confined to patients with pre-existing renal failure, liver disease, or excessive alcohol ingestion. ${ }^{1,2}$ We report a case of fatal lactic acidosis in a patient with no identifiable risk factor.

\section{Case report}

A 49 year old woman presented in 1978 with Type II diabetes. She weighed $56 \mathrm{~kg}$ (ideal body weight $58 \mathrm{~kg}$ ) and was successfully treated with diet, glibenclamide and metformin. In 1983 postprandial plasma glucose levels were 14.5 and $10.7 \mathrm{mmol} / 1$ and her weight was $46 \mathrm{~kg}$, but she refused advice to change to insulin therapy. Her treatment was chlorpropamide $500 \mathrm{mg}$ daily and metformin $850 \mathrm{mg}$ t.d.s. In March 1984 she complained of tiredness and her haemoglobin was $11.0 \mathrm{~g} / \mathrm{dl}$, mean corpuscular volume (MCV) $112 \mathrm{fl}$ (normal 75-95), serum vitamin $B_{12} 57 \mathrm{ng} / \mathrm{l}$ (normal $>150 \mathrm{ng} / \mathrm{l}$ ) and serum folate normal. Plasma urea was $4.8 \mathrm{mmol} / \mathrm{l}$ (normal 3.0-6.5) and plasma creatinine was $91 \mu \mathrm{mol} / 1$ (normal $60-125$ ). Serum intrinsic factor antibody was not detected and serum haptoglobin was present in normal amounts. She declined further investigation. Three months later she presented with anorexia, weight loss, thirst, dyspnoea and tingling of the extremities. Depression and excessive alcohol intake were

Correspondence: D.J. Tymms, M.D., M.R.C.P., Department of Medicine, Royal United Hospital, Bath BA1 3NG, UK.

Accepted: 27 October 1987 denied. Examination was normal, her blood pressure was $130 / 70 \mathrm{mmHg}$ and capillary blood glucose was $10 \mathrm{mmol} / \mathrm{l}$. Plasma electrolytes were normal but the plasma creatinine was $155 \mu \mathrm{mol} / 1$ rising to $347 \mu \mathrm{mol} / 1$ on the following day. These results were not available until she was admitted to hospital after a syncopal attack two days later. On examination she was drowsy, pale and peripherally cyanosed with a pulse rate of $80 / \mathrm{min}$ and systolic blood pressure of $90 \mathrm{mmHg}$. Plasma concentrations were: glucose $0.8 \mathrm{mmol} / 1$, lactate $16.8 \mathrm{mmol} / 1$ (normal 0.6-2.4), sodium $133 \mathrm{mmol} / \mathrm{l} \quad(135-145)$, potassium $6.0 \mathrm{mmol} / \mathrm{l} \quad(3.5-5.0)$, bicarbonate $6.0 \mathrm{mmol} / 1$ and urea $29.6 \mathrm{mmol} / 1$. Arterial blood gas analysis revealed: $\mathrm{pH} 7.027, \mathrm{PCO}_{2} 2.55 \mathrm{kPa}, \mathrm{PO}_{2}$ $19.11 \mathrm{kPa}, \mathrm{HCO}_{3} 4.7 \mathrm{mmol} / \mathrm{l}$. Liver function tests were normal. Haemoglobin was $8.1 \mathrm{~g} / \mathrm{dl}$, MCV $120.5 \mathrm{fl}$ (normal 75-95), serum $\mathrm{B}_{12} 49 \mathrm{ng} / \mathrm{l}$ (normal $>150$ ) and red cell folate normal. The plasma metformin level was $56.8 \mu \mathrm{g} / \mathrm{ml}$ (normal mean therapeutic level $<5.0$ ). Urine output was $350 \mathrm{ml}$ in 24 hours. Despite correction of the hypoglycaemia and acidosis, treatment with peritoneal dialysis and the use of inotropic agents, the patient deteriorated and died 36 hours later. Post-mortem examination revealed evidence of a mild degree of recent renal tubular damage but no hepatic, cardiac or any other significant abnormality.

\section{Discussion}

The very high plasma metformin and lactate levels indicate that the terminal event in this patient was metformin-induced lactic acidosis. The development

(C) The Fellowship of Postgraduate Medicine, 1988 
of acute renal failure immediately prior to its onset may have led to the metformin accumulation. However no cause for the renal failure was found and in particular it preceded the development of shock. An alternative possibility is that the acute renal failure was related directly to metformin toxicity. Although metformin has not previously been reported to be nephrotoxic, acute renal failure and lactic acidosis have been reported to develop comparatively easily in metformin treated patients who had previously normal renal function, in association with gastroenteritis, intravenous pyelography or with diuretic therapy. ${ }^{3}$ Also some patients with apparent chronic renal failure at the onset of lactic acidosis have been shown to achieve almost normal plasma creatinine concentrations after treatment and withdrawal of the biguanide, suggesting that there may be a contributory drug effect. ${ }^{4}$ In this patient the low vitamin $B_{12}$ and macrocytic anaemia were possibly also related to the metformin which may have induced $B_{12}$ malabsorption, ${ }^{5}$ as there was no evidence of haemolysis, folate deficiency or of pernicious anaemia.

The development of hypoglycaemia on the day of admission was probably due to the fact that the patient had taken chlorpropamide on that day and was not eating. This was corrected easily with

\section{References}

1. Hermann, L.S. Metformin: A review of its pharmacological properties and therapeutic use. Diabete Metab 1979, 3: 233-245.

2. Ryder, R.E.J. Lactic acidotic coma with multiple medication including metformin in a patient with normal renal function. Br J Hosp Pract June 1984: 229-232.

3. Assan, R. Heuclin, Ch. Ganeval, D., Bismuth, Ch., George, J. \& Girard, J.R. Metformin-induced lactic acidosis in the presence of renal failure. Diabetologia 1977, 13: 211-217. intravenous dextrose and did not recur. The dose of metformin used in this patient is within the recommended maximum dosage of $3 \mathrm{~g} /$ day (British National Formulary, 1987) and is unlikely to have contributed directly to the development of lactic acidosis. The possibility that the patient took an overdose of metformin cannot be excluded, but there was no evidence to suggest this.

There have been no reports of lactic acidosis due to metformin after 56,000 patient years of its use in Canada, ${ }^{6}$ and there is only one previously reported case in the United Kingdom, which occurred in a patient who abused alcohol. ${ }^{2}$ Our case is exceptional but demonstrates that metformininduced lactic acidosis may occur in a patient with no recognised contraindication to its use. Furthermore regular screening of renal function in this patient would not have been helpful. This case suggests that patients who are underweight and likely to be insulin deficient may be at particular risk from lactic acidosis.

\section{Acknowledgements}

We are grateful to Simbec Research Limited for the analysis of plasma metformin.
4. Luft, D., Schmulling, R.M. \& Eggstein, M. Lactic acidosis in biguanide treated diabetics. A review of 330 cases. Diabetologia 1978, 14: 75-87.

5. Callaghan, T.S., Hadden, D.R. \& Tompkin, G.H. Megaloblastic anaemia due to vitamin $B_{12}$ malabsorption associated with long-term metformin treatment. $\mathrm{Br}$ Med J 1980, 280: 1214-1215.

6. Lucis, O.J. The status of metformin in Canada. Can Med Assoc J 1983, 128: 24-26. 